\title{
Cystitis cystica mimicking as bladder tumour
}

\author{
Shivadeo S. Bapat, L. S. Shah, A. G. Talaulikar, V. R. Kothari, N. K. Shah, D. L. Shah, V. U. \\ Deshmukh
}

Department of Urology, Maharashtra Medical Research Society and Ratna Memorial Hospital, Pune, India

Correspondence: Dr. S. S. Bapat. Address: Urology Department, Maharashtra Medical Foundation's, Ratna Memorial Hospital, 968, Senapati Bapat road, Pune 53, Maharashtra, India. Email: shivadeo@bapats.in.

Received: J une 10, 2012

DOI : $10.5430 / j b g c . v 3 n 1 p 96$
Accepted: December 15, 2012 Online Published: December 26, 2012 URL: http://dx.doi.org/10.5430/jbgc.v3n1p96

\section{Abstract}

Objective: We present our experience of managing six cases of cystitis cystica, which mimicked a bladder tumour. Materials and Methods: Six cases of cystitis cystica were diagnosed over a period of five years (2005-2011). Age varied from 26 to 54 years of which four patients were male and two were females. All of them presented with lower urinary tract symptoms (LUTS), urinary tract infection (UTI) in 3 patients and mild intermittent hematuria in 2 patients. Clinical examination and routine laboratory tests were normal except for presence of leucocytes and blood in urine. Ultrasound (USG) revealed thickened bladder wall with polypoidal lesions suspicious of malignancy. Urinary cytology was negative for malignant cells. Cystoscopy revealed multiple papillary lesions arising from the bladder neck and trigone. There was conspicuous absence of a blood vessel core in the centre of the papillary fronds. Transurethral biopsy of the bladder lesion revealed cystitis cystica with no evidence of malignancy. Four out of six patients responded well to conservative treatment with long-term oral antibiotics as per the culture and sensitivity reports. Transurethral resection was required in only two patients due to lesions causing obstructive symptoms. Patients were followed up with history and clinical examination, urinary cytology and ultrasonographic monitoring of the lesions.

Results: Of the six cases TUR, resection was required in only 2 patients with obstructing lesions and remaining 4 were managed conservatively.

Conclusion: Cystitis cystica is a rare benign condition that can mimic bladder tumour. Cystoscopic appearance is typical and biopsy confirms the diagnosis. Treatment is usually conservative. TUR resection is required in selected cases. Long-term follow up is essential, as cystitis cystica is a premalignant disease of the urinary bladder.

\section{Key words}

Cystitis, Cystitis cystica, Cystitis glandularis

\section{I ntroduction}

There are various benign proliferative and metaplastic conditions of the bladder, but the more common ones are epithelial metaplasia, inverted papilloma, leucoplakia, nephrogenic adenoma, cystitis cystica and cystitis glandularis ${ }^{[1]}$. Among these cystitis cystica and cystitis glandularis have been the most significant pathologically ${ }^{[2-4]}$. These lesions resemble bladder neoplasm on USG and other imaging modality and are a constant threat to transform in to a malignant lesion. 
Cystitis cystic has been a topic for debate and a sourse of anxiety for patients and confusion for the treating urologist. In this article,we present our experience of managing 6 cases of cystitis cystica, which mimicked a bladder tumour.

\section{Materials and methods}

Since January 2005 to January 2011, we treated six patients who presented with symptoms suggestive of lower urinary tract symptoms (LUTS) and concurrent UTI in two patients. Among these sixpatients, four were male and two were females. The age varied from 26 years to 54 years, with a mean age of 39.5 years. Irritative LUTS were predominant in four patients while obstructive LUTS were seen in two male patients. Both the female patients had history of chronic urinary tract infection (UTI). Physical examination was normal in all the patients with soft, nontender abdomen and normal pelvic examination. None of the patients gave any history of exposure to industrial carcinogens, or chronic smoking or any significant past medical or surgical illness. None of the patient had a history of tuberculosis in the past. Routine hematological and renal function tests were within normal limits in all the patients. Urine analysis showed UTI in three patients. Urine culture of these three patients showed E-coli with colony count $<1000000$, sensitive to majority of antibiotics. Urine cytology revealed no malignant cells (see Table 1). Ultrasonography of abdomen and pelvis revealed evidence of thickened bladder wall with polypoidal lesions highly suspicious of malignancy in all patients (see Figure 1 \& 2). All patients underwent cystoscopic evaluation and biopsy under short general anesthesia. After cystoscopic confirmation of the lesion, biopsy was taken with a resectoscope loop to include superficial bladder muscle (see Figure 3). Specimen was sent for histopathological examination. After hemostasis, bladder was drained till next day and the patients were discharged.

Table 1. Patient demographics and investigations

\begin{tabular}{|c|c|c|c|c|c|c|c|}
\hline Sr. No & Age(yrs) & Sex & $\begin{array}{l}\text { Presenting } \\
\text { symptoms }\end{array}$ & Urineanalysis & Urine Culture & Cytology & USG \\
\hline 1 & 34 & M & $\begin{array}{l}\text { Irritative } \\
\text { LUTS }\end{array}$ & Normal & Negative & Negative & $\begin{array}{l}\text { Polypoidal mass arising from } \\
\text { inferior wall of bladder }\end{array}$ \\
\hline 2 & 37 & $\mathrm{~F}$ & $\begin{array}{l}\text { Chronic } \\
\text { UTI }\end{array}$ & UTI & E-coli ++ & Negative & $\begin{array}{l}\text { Bladder wall thickened }>1.5 \\
\mathrm{~cm} \text { at trigone }\end{array}$ \\
\hline 3 & 50 & $\mathrm{~F}$ & Mild UTI & UTI & E-coli ++ & Negative & $\begin{array}{l}\text { Papillary mass arising from } \\
\text { trigonal region? malignant }\end{array}$ \\
\hline 4 & 26 & M & $\begin{array}{l}\text { Obstructive } \\
\text { LUTS }\end{array}$ & Normal & Negative & Negative & Ca bladder at base \\
\hline 5 & 42 & $\mathrm{M}$ & $\begin{array}{l}\text { Chronic } \\
\text { UTI }\end{array}$ & UTI & E-coli ++ & Negative & $\begin{array}{l}\text { Papillary mass with } \\
\text { calcification? calculus }\end{array}$ \\
\hline 6 & 48 & $\mathrm{M}$ & $\begin{array}{l}\text { Irritative } \\
\text { LUTS, with } \\
\text { colicy pain }\end{array}$ & Normal & Negative & Negative & $\begin{array}{l}\text { B/L HN, HU polyploidal } \\
\text { lesion at UVJ }\end{array}$ \\
\hline
\end{tabular}

Note. HN - Hydronephrosis, HU - Hydroureter, UVJ - ureterovesical junction

\subsection{Observations}

Cystoscopy revealed normal urethra in all the patients. Bladder neck was wide open in 5 out of 6 patients, and obstructed in one male patient who had huge papillary lesions obstructing the bladder neck. Trigone of all the patients showed multiple, diffuse papillary frondlike lesions spreading from the bladder neck on to the trigone like a carpet. In one patient the papillary growth was involving the left ureteric orifice producing obstruction and stasis in the left ureter. The obstructing growth over the left ureteric orifice was resected. The papillary frond like lesion, causing obstruction to bladder outlet was the cause of obstructive and irritative lower urinary track symptoms in one male. These lesions were either closely grouped together or were solitary. They were having their own mucous membrane covering, filled with clear serous fluid. Important finding was absence of a blood vessel in the centre of the frond, which is a characteristic of a neoplastic 
papillary mass. The surrounding mucosa was normal in appearance. They did not reveal any other signs of malignancy like bleeding on touch or field change. The rest of the bladder mucosa was essentially normal in all the patients. Biopsy with resectoscope loop including superficial bladder muscle was taken in all the patients (see Figure 3).

Figure 1. Polypoidal lesion close to left UVJ causing hydroureter

Figure 2. Trigonal mass like lesion mimicking malignant lesion on ultrasonography

Figure 3. Typical cystoscopic view of papillary frond just prior to biopsy. Note the absence of central blood vessel in the papillary frond.

Figure 4. Typical histopathological features suggestive of cystitis cystica
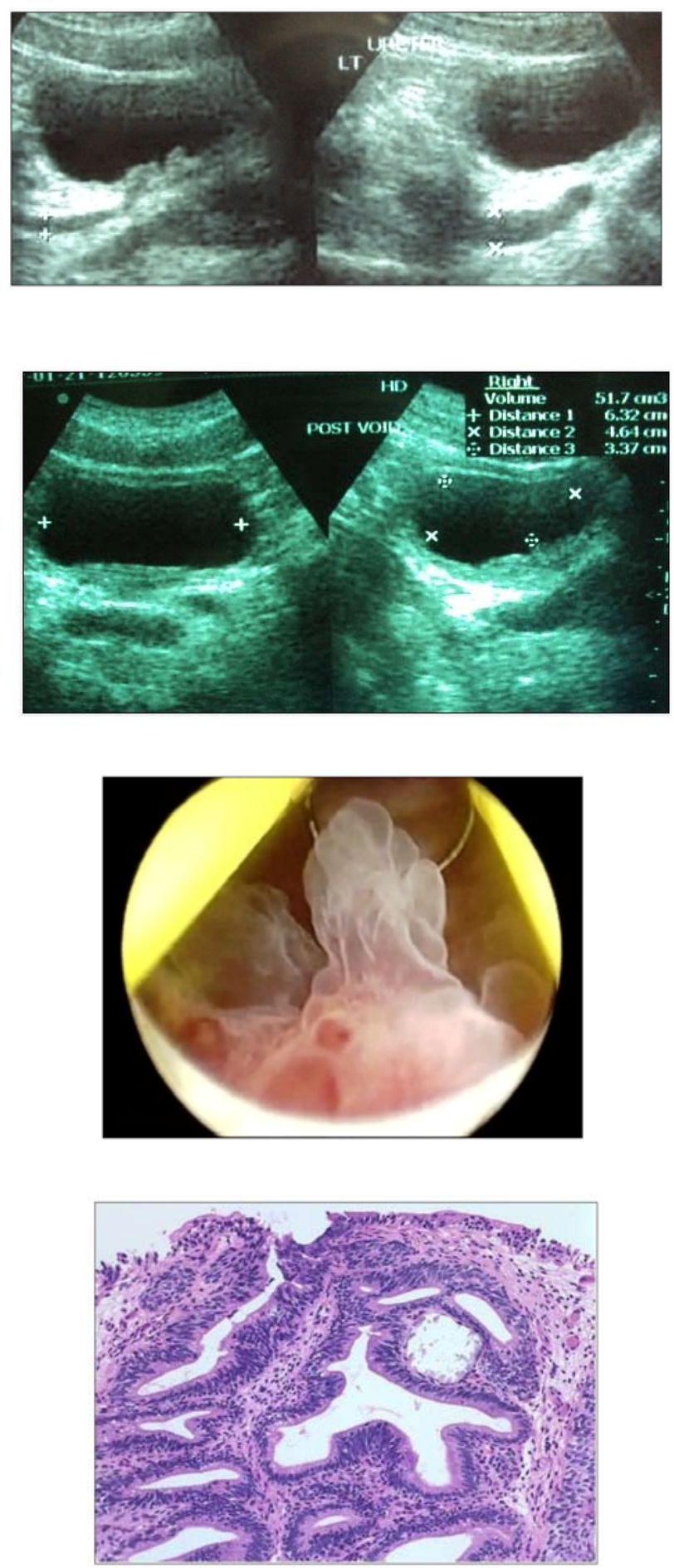

Histopathology report of all the patients confirmed the diagnosis of "Cystitis Cystica with features of Cystitis Glandularis”. The typical features of Von Brunn nests hyperplasia into lamina propria causing clefts and crypts with gland 
like differentiation lined by columnar or cuboidal cells was distinctly seen in these slides (see Figure 4) ${ }^{[3]}$. There was no evidence of anaplastic or dysplastic features suggestive of malignant transformation in the submitted specimens.

\subsection{Complications}

None of the patients had any significant complication pertaining to anesthesia or cystoscopic biopsy. 2 out of 6 patients required TUR resection of the whole lesion for symptomatic relief. Reflux related symptoms following resection were seen in one patient, which resolved on their own.

\section{Discussion}

Cystitis cystica and cystitis glandularis are considered as premalignant lesion of the urinary bladder. The literature mentions that TUR resection of the lesions and treatment of precipitating factors is required for these lesions ${ }^{[1]}$. Also regular follow up with ultrasonography and cystoscopy is indicated for the fear of malignant transformation that might rarely occur ${ }^{[10,13]}$.

In the present study, the histopathological report in all the six patients confirmed the diagnosis of cystitis cystica with an element of cystitis glandularis with no features suggestive of malignancy. Each one of them was managed with proper counseling for long-term antibiotics usage, need for regular 6-12 monthly follow up with urine cytology and ultrasonography. Antibiotics were given as per the urine culture and sensitivity report.

Of the 6 patients, two male patients and both the females responded well to the conservative treatment and are on regular follow up. Two male patients with predominant obstructive symptoms did not respond to conservative treatment. They underwent TUR resection of the lesion in subsequent follow up.

All the patients were followed up with a regular six monthly urine culture, cytology and ultrasound to monitor the lesion. Follow up cystoscopy was done in patients with persistent LUTS, hematuria or increase in size of lesions on ultrasound.

We strongly recommend conservative management in all the patients. A cystoscopy and Biopsy of the representative lesion under general anesthesia with resectoscope loop is safe, quick, cost effective and a more efficient way to achieve diagnosis and treat these patients. TUR resection should be done in few selected cases such as patients who have failed conservative management; patients with obstructive lesions and in patients showing increase in size of the lesions during follow up.

We do not recommend cystoscopy during follow up as a routine but only for those patients who had persistent LUTS, hematuria, increase in size of lesions on ultrasound or with risk factors for carcinoma bladder. In addition, patients with mucus secretions, intestinal metaplasia and pelvic lipomatosis need close surveillance with cystoscopy as malignant transformation of cystitis cystica is reported in these lesions ${ }^{[10-13]}$.

\section{Conclusion}

Cystitis cystica is a rare condition mimicking malignancy of urinary bladder. Cystoscopy and biopsy helps to confirm the diagnosis. Patients can be managed conservatively. Transurethral resection is required in few selected patients with obstructive lesions, failure of conservative treatment and recurrence or increase in size of lesions. Follow up should be done six monthly with urinary cytology and ultrasound. Where as cystoscopy is indicated in patients with persistent LUTS, hematuria, increase in size of lesions on ultrasound or with risk factors for carcinoma bladder. Patients with mucus secretions, intestinal metaplasia ${ }^{[1,10]}$, pelvic lipomatosis ${ }^{[1,11,12]}$ should be kept on a close follow up protocol, which includes cystoscopy at 6 monthly intervals. 


\section{References}

[1] David P Wood, JR., Urothelial Tumors of The Bladder. Campbell - Walsh Urology. TENTH EDITION Saunders. Elsevier: 2012: 2310-11.

[2] Vivvan J Harris, M Javedpour, Giovanni Fizzotti. Cystitis cystica masquerading as bladder tumour. AJR. February 1974; 120: 410-412.

[3] Singh I, Ansari MS. Cystitis cysticaglandularis masquerading as a bladder tumour. IntUrolNephrol. 2001; 33(4): 635-6. PMid:12452616 http://dx.doi.org/10.1023/A:1020511826666

[4] Semins MJ, Schoenberg M P. A case of florid cystitis glandularis. Nat clin Prac Urol. 2007; 4: 341-5.

[5] Manco, L. G. Cystitis cystica simulating bladder tumour at sonography. Journal of Clinical Ultrasound. $1985 ; 13: 52-54$. http://dx.doi.org/10.1002/jcu.1870130114

[6] Golf GB. Cystitis cystica and cystitis glandularis: cause of bladder mass. J Comput Assist Tomogr. 1983 Apr; 7(2): 347-9. http://dx.doi.org/10.1097/00004728-198304000-00031

[7] Jost SP, Dixon JS,Gosling JA. Ultrastructural observations on Cystitis cystica in human bladder urothelium. Br J Urol. 1993; 71(1): 28-33. PMid:8435733 http://dx.doi.org/10.1111/j.1464-410X.1993.tb15875.x

[8] Krishnamoorthy S, Korula A, Kekre NS. The nested variant of transitional cell carcinoma of urinary bladder: An aggressive tumour with a bland morphology. Indian J Urol. 2006; 22: 378-80. http://dx.doi.org/10.4103/0970-1591.29133

[9] Edward P D, Hurm R A, Jaeschke W H. Conversion of Cystitis Glandularis to adenocarcinoma. J Urol. 1980; 108: 568-70.

[10] Smith AK, Hansel DE, Jones JS.Role of cystitis cysticaetglandularis and intestinal metaplasia in development of bladder carcinoma. Urology. 2008; 71(5): 915-918. PMid:18455631 http://dx.doi.org/10.1016/j.urology.2007.11.079

[11] Buckley O, Geoghegan T, Feeney J, Crotty P, Torreggiani WC. Answer to case of the month \#126. Pelvic lipomatosis in association with cystitis glandularis. Can AssocRadiol J. 2007 Dec; 58(5): 300-2. PMid:18286907

[12] OlsenB, Johansen TE, Majak BM Cystitiscystica-a premalignantcondition? Tidsskr Nor Laegeforen. 1993; 113: 2255-6. PMid:8362391

[13] Salm, R. NEOPLASIA OF THE BLADDER AND CYSTITIS CYSTICA. British Journal of Urology. $1967 ; 39: 67-72$. http://dx.doi.org/10.1111/j.1464-410X.1967.tb11786.x 